\title{
Patients characteristics and outcomes of prolonged mechanical ventilation after critical illness transferred to a weaning unit
}

\author{
J Rubio ${ }^{1 *}$, JA Rubio Mateo-Sidron², E Palma Gonzalez ${ }^{2}$, R Sierra Camerino ${ }^{3}$, F Carmona Espinazo ${ }^{3}$, F Fuentes Morillas ${ }^{2}$ \\ From ESICM LIVES 2015 \\ Berlin, Germany. 3-7 October 2015
}

\section{Introduction}

Recent trends seem to point out that growing numbers of patients requiring prolonged mechanical ventilation (PMV) and protracted weaning after critical illness with eventually account for a large portion of all Intensive Care Unit (ICU) cost and bed occupancy. Specialized Weaning Unit (WU), may facilitate weaning through focused multidisciplinary expert team, but due to considerable variability of interventions and organization outcomes remain unclear.

\section{Objectives}

To characterize patients, risk factors and outcomes of patients who require tracheostomy, PMV and weaning after critical illness and are transferred to a WU.

\section{Methods}

A retrospective, descriptive study of tracheostomized and clinically stable patients who required PMV $(>21$ days) and weaning ( $>7$ days) admitted to a 23-bed university intensive care unit and were transferred to a WU over a 4-year period (2011-2014) after critical illness. Demographics characteristics, clinical status at admission, reasons for needing PMV, complications and clinical status at discharge were recorded and analysed from clinical charts and electronic databases. Basic descriptive statistics are presented, mean \pm SD, median (interquartile range), and percentages.

\section{Results}

Twenty-six patients were included in the study. Most were male (57.7\%). Age 60,88 \pm 16.5 years. APACHE II score 27.5 (12 - 46). The most frequent admission category was

${ }^{1}$ Hospital Puerta del Mar, ICU, Cádiz, Spain

Full list of author information is available at the end of the article medical (61.5\%), and the main diagnostics groups were neurological $9(34,6 \%)$ and respiratory $(15,4 \%)$. ICU and WU length of stay were 45.5 (11 - 88) and 74.5 (3 - 244) days respectively, with an in-hospital mortality rate of $15.4 \%$. The main reasons for mechanical ventilation in WU were neuromuscular illness (73\%), and were on mechanical ventilation for 84 ( 4 - 533) days. Seven-teen (65.4\%) patients were discharged to home, $76.5 \%$ of them could be decannulated and $35 \%$ were out with mechanical ventilation. Four (15.4\%) patients were transferred to other long-care facilities.

\section{Conclusions}

This specific WU care resulted in low mortality rates, high success of weaning and considerable home discharge rates of ICU patients with prolonged mechanical ventilation and weaning.

\section{Authors' details}

${ }^{1}$ Hospital Puerta del Mar, ICU, Cádiz, Spain. ${ }^{2}$ Hospital Infanta Cristina, Badajoz, Spain. ${ }^{3}$ Hospital Puerta del Mar, Cádiz, Spain.

Published: 1 October 2015

\section{References}

1. Rose L, Fraser IM: Patient characteristics and outcomes of a provincial prolonged-ventilation weaning centre: A retrospective cohort study. Can Respir J 2012, 19(3):216-220.

2. Lone NI, Walsh TS: Prolonged mechanical ventilation in critically ill patients: epidemiology, outcomes and modelling the potential cost consequences of establishing a regional weaning unit. Critical Care 2011, 15(2):R102.

3. Bigatello LM, Stelfox HT, Berra L, et al: Outcome of patients undergoing prolonged mechanical ventilation after critical illness. Crit Care Med 2007, 35(11):2491-2497.

doi:10.1186/2197-425X-3-S1-A318

Cite this article as: Rubio et al:: Patients characteristics and outcomes of prolonged mechanical ventilation after critical illness transferred to a weaning unit. Intensive Care Medicine Experimental 2015 3(Suppl 1):A318.

\section{SpringerOpen $^{\circ}$}

(c) 2015 Rubio et al.; This is an Open Access article distributed under the terms of the Creative Commons Attribution License (http:// creativecommons.org/licenses/by/4.0), which permits unrestricted use, distribution, and reproduction in any medium, provided the original work is properly cited. 